\title{
Bicentenario de la independencia: Teorías, paradigmas y obra educativa en el gobierno de Simón Bolívar (1822-1827)
}

\author{
Andrés Alfaro Lagos, Berta Chonlong Pomacaja, \\ Carlos Felipe Paucar, Teodosio Olarte Espinoza* \\ Universidad Nacional de Educación Enrique Guzmán y Valle, Lima, Perú \\ Wilfredo Kapsoli Escudero \\ Universidad Ricardo Palma, Lima, Perú \\ wckapsoli @ hotmail.com
}

\begin{abstract}
RESUMEN
El presente trabajo enfoca la obra educativa del Libertador Simón Bolívar, que necesariamente va con el estudio de su maestro Simón Rodríguez que fue su guía en su formación. Rodríguez, maestro innovador y rebelde del ocaso colonial y en el advenimiento de la independencia, maestro de la república. En la organización de la república desarrolla su proyecto educación popular que intenta beneficiar a las grandes mayorías nacionales, marginadas durante los trescientos ańos de dominio colonial. Reivindica el derecho a la educación de la mujer, la educación para el trabajo, la práctica de valores, la profesionalización del docente, critica al modelo lancasteriano. El Libertador, desarrolló una basta política de educación, primero bajo la influencia del modelo lancasteriano y después del arribo de su maestro Simón Rodríguez, con el modelo de la educación popular cuyas manifestaciones más saltantes son la creación de la Universidad de Trujillo, el Colegio de Santa Rosa de Ocopa, el Colegio de Artes y Ciencias y de Educandas del Cusco, el de Ciencias y Artes de Puno, Gineceo de Lima, creación de escuelas normales entre otros.
\end{abstract}

Palabras Clave: Bolívar, Rodríguez, modelo lancasteriano, educación popular, educación para el trabajo

\section{Bicentennial of the Independence: Theories, paradigms and educational work in the government of Simón Bolívar (1822-1827)}

\begin{abstract}
This paper focuses on the educational work of the Liberator Simón Bolívar, which necessarily goes along with the study of his mentor Simón Rodríguez, who was his guide during his formation. Rodríguez was an innovative and rebellious teacher of the colonial decline and in the advent of independence, a master of the republic. In the organization of the republic he developed his popular education project to benefit the great national majorities marginalized during the three hundred years of colonial power. He reclaimed the right to women's education, education for work, practice of values, professionalization of the teacher. $\mathrm{He}$ criticized the Lancasterian model. The Liberator developed a vast education policy, first under the influence of the Lancasterian model and after the arrival of his mentor Simón Rodríguez, with the popular education model. His most relevant representations are the creation of the University of Trujillo, el Colegio de Santa Rosa de Ocopa, el Colegio de Artes y Ciencias y de Educandas del Cusco, el de Ciencias y Artes de Puno, Gineceo de Lima, the creation of normal schools, among others.
\end{abstract}

KeYworDs: Bolívar, Rodríguez, Lancasterian model, popular education, education for work

* Andrés Alfaro Lagos (andrealfarol@yahoo.es), Berta Chonlong Pomacaja (bertachonglong@gmail.com), Carlos Felipe Paucar (unecafp@gmail.com), Teodosio Olarte Espinoza (teo_ateo@yahoo.es). 


\section{Introducción}

Aprovechamos el interés y las manifestaciones de la conmemoración del Bicentenario de la Independencia, para recordar y conmemorar los movimientos sociales, protagonizados por nuestros antepasados, en su lucha contra el colonialismo espańol. Tocó a Bolívar protagonizar, en el escenario andino, hechos históricos importantes, condujo al Ejercito Libertador a las victorias de las batallas de Junín (6/VIII/1824) y Ayacucho (9/ XII/1824) que sellaron el derrumbe del colonialismo español y el logro de la Independencia política del Perú y de América. La investigación tiene como propósito principal estudiar la obra educativa en el gobierno del Libertador en relación con los modelos educativos paradigmáticos que moldearon su pensamiento pedagógico y de su maestro. Encontramos un enorme despliegue de aparatos legales en beneficio de la educación en las nacientes repúblicas, sea a través de su propia firma o la de sus representantes en el Consejo de Gobierno de Lima. Inicialmente influenciado por el método lancasteriano y después de la victoria de Ayacucho, influenciado por su maestro Rodríguez. El Libertador emprendió una notoria campaña en favor de una educación popular, igualitaria y republicana, lo cual terminó por debilitar las bases del antiguo sistema educativo colonial. De esta forma, el periodo de Bolívar vio nacer la Universidad de Trujillo, escuelas públicas, escuelas normales, establecimientos educativos para mujeres como el Colegio de Educandas del Cuzco, el Gineceo de Lima, además de impulsar la labor docente, la enseñanza de las artes y la edificación de museos en la capital.

Consideramos que las propuestas educativas de Rodríguez y Bolívar no podrían ser clasificadas como "teorías educativas" en el sentido estricto de la palabra. Ambos personajes desarrollaron argumentos sobre cómo debería realizarse el proceso de enseñanzaaprendizaje, la relación entre el profesor y su estudiante, los conocimientos a impartirse y la evaluación de los mismos; sin embargo, sus obras no presentan un sistema articulado de conocimientos basado en conceptos, supuestos, principios, postulados, teorías, leyes y metodologías científicas propias de indagación y aproximación a un determinado objeto de estudio. Realizada esta advertencia, nosotros optamos por considerar sus argumentos como parte de un "pensamiento educativo", el cual fue resultante de la lectura o influencia de modelos educativos paradigmáticos desarrollados en Europa en el siglo XVIII o inicios del XIX, como el método mutualista de Joseph Lancaster, el naturalismo pedagógico de Jean Jacques Rousseau y los logros educativos de la Revolución Francesa. He ahí la razón de incluir la categoría "paradigma" en el título del presente estudio, pues la obra educativa en el gobierno de Bolívar estuvo influenciada por un conjunto de postulados propios de su tiempo, los cuales eran innovadora y relativamente nuevos para la América colonial.

Nuestra investigación utilizó las fuentes primarias y secundarias, para estructurar los resultados de la investigación, de manera descriptiva, interpretativa y critica. 
Igualmente utilizamos el enfoque multimetodico con los métodos: analítico-sintético, deductivo-inductivo, dialéctico, historia-problema, hermenéutico. Tenemos que aclarar que el problema de la pandemia, dificultó la investigación en vista de que la mayoría de los integrantes, del equipo, somos personas de riesgo, pero pudimos solucionar con la bibliografía particular y virtual que existe.

Dentro de los resultados de la investigación, comenzamos con un breve pero oportuno repaso de los aspectos más resaltantes del pensamiento educativo de Simón Rodríguez, centrándonos en su propuesta de educación popular y la influencia que recibió del modelo educativo paradigmático de Rousseau. Es prácticamente imposible estudiar la obra educativa en el gobierno de Bolívar sin antes dedicarle algunas líneas a Rodríguez, pues fue el maestro del Libertador en su infancia, compañero de andanzas en las diferentes ciudades y en el logro de mayor preparación académica del Libertador en Europa. Además, a la vuelta de Rodríguez (1823) a la Gran Colombia y su llegada al Perú, su desempeñó como Director de Enseñanza Pública o Ministro de Educación, tanto en Perú y Bolivia entre 1825 y 1826. Si bien su nombre no aparece en la legislación educativa bolivariana, es detectable su influencia durante la investigación y lectura de los mismos.

\section{Pensamiento educativo de Simón Rodríguez}

Simón Rodríguez, un destacado caraqueño joven de veinte años, educador, filósofo y gran conocedor y practicante de las ideas de la Ilustración, lector de las obras de Juan Jacobo Rousseau, particularmente del Emilio (1762) y por lo tanto seguidor de la escuela naturalista que según Caro (2006) "Los naturalistas propugnan la maduración espontánea y libre del educando que, por naturaleza -dicen- encierra posibilidades excelentes de desarrollo" (p.120). En realidad, las aplicaciones de esta nueva escuela pedagógica era producto de un nuevo amanecer, difícilmente comprendida por los sectores de la vieja feudalidad. Fue un maestro, que aplicó a la realidad social latinoamericana, los pensamientos revolucionarios de educación que se daban en ese contexto. Peńaloza (2001) comenta su pensamiento: "Nosotros nos hemos caracterizado por ser imitadores. Imitamos ¡Y por qué!, -se pregunta don Simón Rodríguez-, “¡porque imitamos a los europeos?", será porque los europeos crearon lo suyo, ellos lo inventaron, no lo copiaron de ninguna parte. Los europeos crearon este sistema, pero no lo tomaron del África ni de Asia, ni de ningún sitio. Lo crearon ellos. Y Simón Rodríguez dice: "Y Porque no imitamos a los europeos en lo más importante que es, no en imitarles, ¿sino en crear?” (p.19). En América colonial y poscolonial nos hemos acostumbrado a no crear sino simplemente a copiar, no existe un espíritu nacional, sino colonial. Según I Lavretski (1986) siempre solía decir "Yo no quiero parecerme a un árbol arraigado en 
un solo lugar quiero parecerme al viento, al agua y a todas las cosas que están en perpetuo movimiento" (p.15). Lo que demuestra que era un hombre muy activo, en sus responsabilidades educativas y otras. Dentro su concepción religiosa era ateo, no creía en Dios, su ateísmo le creo serios problemas, en una sociedad impregnada fuertemente al feudalismo. En su condición de maestro tienen dos etapas: Maestro colonial y maestro republicano:

\section{El Maestro en la Sociedad Colonial}

En pleno periodo colonial el Ayuntamiento de Caracas le encargó dirigir una escuela dedicándose a estudiar su problemática educativa desde 1791. Conoció la realidad social y política de las escuelas venezolanas, lo que lo llevó a escribir un informe para el Cabildo de Caracas en 1794 y reelaborado al ańo siguiente a causa del deterioro del primero, titulado Reflexiones sobre los defectos que vician la Escuela de Primeras Letras en Caracas y medios de lograr su reforma por un nuevo establecimiento. Inicialmente, el informe fue aprobado y sus recomendaciones puestas en marcha el 5 de junio de 1795; sin embargo, al poco tiempo, el Cabildo dio un informe negativo del mismo. Con esto, Rodríguez renunció a la escuela, mas no a su pensamiento crítico sobre el estado de la educación y las nuevas ideas para reformarla. Ocampo L (2007) refiere: "El Maestro Rodríguez tuvo el convencimiento que la educación en Caracas estaba viciada y necesitaba de una reforma integral. Las clases altas eran ociosas e ignorantes y vivián entre prejuicios anacrónicos. Nadie estudiaba lo que debía saber y nadie aprendía para mejorar su vida” (p. 83). Era la lucha entre las concepciones de la vieja feudalidad impregnada en los sectores conservadores y las innovadoras nacidas con el movimiento de la Ilustración y la Revolución Francesa.

También se preocupó por la educación de la mujer, que durante la colonia habían sido marginados. Con motivo de su matrimonio con María de los Santos Ronco, el 25 de junio de 1793, Ocampo (2007) refiere: "Y en su interés por la educación para la mujer, en noviembre del mismo ańo, se dirigió al Cabildo de Caracas con una representación para proponer la creación de una Escuela de Niñas para Caracas” (p. 83). Como vemos practicaba el respeto a los derechos humanos y el derecho de la mujer a la educación una posición revolucionaria en ese contexto.

\section{El Maestro en la Sociedad Republicana}

Rodríguez retornó a tierras sudamericanas, en 1823, después de haber estado fuera de ella durante más de veinte años y de haber visto los cambios políticos, económicos y so- 
ciales producidos por la revolución francesa, en todo Europa, que liquido la tiranía y las monarquías absolutas. Desde entonces, desplegó una importante labor educativa, como maestro republicano primero de la mano de Bolívar, mientras el Libertador estuvo en la cúspide del poder y luego cuando el Libertador cae en desgracia y renuncia al poder y pierde apoyo de Sucre, como maestro y escritor independiente.

\section{La Educación Popular}

Rodríguez proclamó en su Sociedades que la instrucción debía ser general, sin excepción, extensiva para todas las realidades sociales y económicas. Privar a un hombre de los conocimientos, los cuales necesita para entenderse con sus semejantes, era prácticamente un acto de inhumanidad. Sin el conocimiento, la existencia se volvería precaria y la vida miserable.

Para Rodríguez, la educación era una necesidad, un derecho natural, del cual todos debían gozar. Concebía a la educación como un fenómeno social, multiplicador y formativo que debía beneficiar a todos los sectores sociales que no habían tenido acceso, durante el periodo colonial, conformado por los hijos de los indígenas, esclavos, mestizos, etc. había llegado el momento de reivindicarlos y prepararlos para el desempeño en la nueva vida en una democracia, popular y republicana. La educación debería de estar a cargo del Estado, su propuesta de educación popular era, sin duda, un hijo de su tiempo, un hijo de la Ilustración, pero su aplicación en la realidad tuvo que esperar incluso hasta el siglo XX. Definitivamente Simón Rodríguez, era un maestro rebelde, innovador del contexto social de fines de la colonia e inicios de la vida independiente en los países bolivarianos.

En ese contexto los hijos de la población vulnerable terminaban en casas de misericordia, conventos, cárceles u hospicios, lugar donde aprendían a servir, para merecer la preferencia de ser vendidos o entregados como criados fieles o esposas inocentes. La educación debía ser horizontal para todos, tanto en condiciones materiales como en las materias desarrolladas, Rodríguez, (1916) señala en el siguiente párrafo:

Los niños se habían de recoger en casas cómodas y aseadas, con piezas destinadas á talleres, y estos surtidos de instrumentos, y dirijidos (sic.) por buenos maestros. [...] Todos debían estar decentemente alojados, vestidos, alimentados, curados y recibir instrucción moral, social y relijiosa (sic.). (pp. 167-168)

El desarrollo del servicio educativo debía ser en favor del florecimiento del sistema republicano. A través de la educación se logra la formación de buenos ciudadanos y se moldea las voluntades para el futuro republicano. 
El maestro Rodríguez también se preocupó por la educación moral de la sociedad y la reproducción de virtudes sociales. Consideraba que cada hombre ponía sus ojos y oídos en contacto con los movimientos y los efectos de otro hombre: ve lo que hace, y oye lo que dice. En este sentido, jugaba un papel importante el ejemplo, el modelo que podía ofrecer el docente, por lo que se necesitaba de "Maestros que enseñen con sus Modales" (Rodríguez, 1842, p. 34). El maestro es un referente de la comunidad y de la institución más importante la escuela, las buenas costumbres podían ser imitadas por los estudiantes; los profesores debían de mostrar gestos, ademanes, lenguaje y actitudes correctas y decentes, su comportamiento debía corresponderse con el de un verdadero maestro. No olvidemos que la influencia de los maestros usualmente tiene alcance local o regional, pero en algunos casos tienen alcance nacional.

Para Rodríguez (1842), lo que se ve continuamente se hace ley, por lo que el sistema educativo debía tener muy en cuenta el qué, de quién y de dónde se ha aprendido, pues "la ignorancia se sostiene por ignorancia" (p. 36). El maestro Rodríguez demuestra en su práctica social su compromiso por la independencia de los pueblos de Latinoamérica, de la opresión colonial; interés por practicar los más altos valores morales, en beneficio de la patria y la república. La cuestión moral también fue preocupación del Libertador, lo presentó en el proyecto de Constitución de Angostura, con el nombre de El Poder Moral; igualmente lo siguió desarrollando en otros documentos sobre la educación moral, como el contenida en la carta escrita a Guillermo White, desde San Cristóbal, el 28 de mayo de 1820; encontrándose en el Alto Perú, firmó un Decreto contra la pornografía de folletos impuros, estampas, cajas, sellos y abanicos obscenos y a todo lo que conduce a la inmoralidad.

\section{Profesionalización de la Docencia}

El maestro Rodríguez a través de sus páginas, escrita en Reflexiones argumentaba sobre la necesidad de profesionalizar la práctica docente y alcanzar una adecuada remuneración para los mismos, la sistematización de un método de enseńanza más claro y preciso, el aumento del número de escuelas y docentes en ellas, la importancia de la enseńanza para el Estado y la sociedad, la dación de premios en lugar de castigos, etc.

Rodríguez (2016a) es el primero en reconocer el encargo social de la profesionalización de la enseñanza, pues "Todos se consideran capaces de desempeńarla”, dejando de lado la formación profesional docente (pp. 21-28). De esta forma, defendía la necesidad que el título profesional debía dársele "al que SABE enseñar", es decir, "el que enseña a aprender, no al que manda aprender, o indica lo que se ha de aprender, ni al que aconseja que se aprenda” (Rodríguez, 1849, 12 de mayo, p. 151). En otras palabras, el maestro debía ser el que enseńa a aprender y ayuda a comprender, pues entre saber 
para sí y saber transmitir hay una gran diferencia. Cuando reconoce su profesionalización del docente, deducimos es la réplica de este merecido reconocimiento hecha por los logros de la Revolución Francesa, al docente, con la creación de la Ecole Normale de Paris, realizado el 30 de octubre de 1794, con el objetivo de formar a los docentes de ese entonces. En el caso de Latinoamérica la primera institución formadora de docentes fue fundada en el Perú, durante el protectorado de San Martin, el 6 de julio de 1822, cuyo primer director fue el escoces misionero Diego o James Thompson, que aplicó el sistema lancasteriano. El Libertador Bolívar (1823-1826), para luchar contra el analfabetismo heredado de la colonia y preparar a los sujetos que iban a conducir el proceso de enseñanza-aprendizaje decretó en Lima, el 31 de enero de 1825, la creación de escuelas normales lancasterianas en cada capital de departamento y de esta influir en el resto de pueblos del interior del país.

\section{Educación para el Trabajo}

Es otro de los aportes en el pensamiento educativo del maestro Rodríguez, el mismo que marcha paralelo con la preparación cognitiva, además de la preparación en valores. Preparar a los estudiantes en aspectos relativos al trabajo en el futuro le serian de mucha utilidad.

La educación para el trabajo o educación técnica es un aspecto importante en la obra de Rodríguez (1849), lo cual se hace explícito en sus textos: “Toca a los Maestros hacer conocer a los niños el valor del trabajo, para que sepan apreciar el valor de las obras" (p. 138). Los oficios manuales, muy menospreciados para ese entonces, debían formar parte del currículo de enseñanza de los varones en las escuelas: albañilería, carpintería y herrería. Mientras que, para el caso de las mujeres, ellas debían aprender "los oficios propios de su sexo" (Rodríguez, 1916, p. 168). Se debía de dar instrucción al varón para no volverlo ocioso, y a la mujer para no verla prostituida o en matrimonios convenidos. Su intención no era la de llenar el país de "artesanos rivales ó miserables", sino de instruir y acostumbrar al trabajo a los individuos para crear hombres útiles para el Estado: era "colonizar el país con sus propios habitantes" (Rodríguez, 1916, p. 169). Estas propuestas tuvieron sin duda una réplica de ciertos sectores conservadores pues el trabajo manual ha sido históricamente menospreciado dentro de las clases sociales acomodadas, particularmente en las sociedades donde predomina la feudalidad que van contra toda acción liberadora.

Simón Rodríguez, es uno de los pocos maestros que emitió un "juicio crítico a la práctica y propuesta lancasteriana” o enseñanza mutua de Joseph Lancaster, no creía en la eficacia real del método en la formación de los ciudadanos republicanos. En el caso del Perú había sido adoptado desde el Protectorado de San Martín; inclusive se había 
adoptado en Argentina, Uruguay, Ecuador y Chile. En las disposiciones educativas iniciales del Libertador Bolívar, desde la Gran Colombia y el Perú adoptó este sistema en las repúblicas andinas, inclusive Sucre era partidario de la propuesta lancasteriana. En la Gran Colombia estuvo presente el propio Lancaster, implementando su propuesta educativa en las instituciones educativas, que había expuesto ante Bolívar y Miranda en Londres en 1810.

El maestro Rodríguez, desde cuándo empezó a trabajar por la educación y a su vuelta de Europa planteo la educación popular y lo aplicó en Bogotá y desde cuando acompañó al Libertador en el Perú y el Alto Perú. Con posterioridad estando en Latacunga-Ecuador escribe el texto los Consejos de Amigo al Colegio de San Vicente de Latacunga; (2001) en este texto combate infatigablemente el método lancasteriano refiere en su manuscrito elaborado a mediados de 1850, que:

ENSENAANZA MUTUA es un disparate. Landcáster (sic.) la inventó, para hacer aprender la Biblia DE MEMORIA. Los discípulos van a la Escuela a APRENDER, no a ENSEÑAR ni a AYUDAR a ENSENAAR. Dar GRITOS i hacer RINGORRANGOS no es aprender a LEER ni a ESCRIBIR. Andar recitar, de memoria, lo que NO SE ENTIENDE es hacer PAPAGALLOS, para que por LA VIDA sean CHARLATANES. (p. 25)

Según Rodríguez, el lancasteriano exigiría un rigor y una disciplina militar casi impracticables para funcionar, además de que el contenido se transmitía de manera superficial y centrado en el adoctrinamiento religioso. Rodríguez abogó por una enseñanza que se comprenda, que sea de utilidad, que comprenda el respeto y atención hacia el trabajo práctico y manual.

En suma en el estudio de la historia de la educación y la cultura de América Latina revela la existencia de un número considerable de educadores que generaron un pensamiento educacional y pedagógico que se caracteriza por su estrecha vinculación con el proceso de independencia nacional y continental, cómo se ha visto hasta aquí, el pensamiento educativo de Simón Rodríguez, maestro del Libertador y su mano derecha entre 1825 y 1826 , podemos resumirlo en su propuesta de “educación popular", caracterizada por ser una educación formal o profesional, dirigida por igual a todas las clases, basada en virtudes y actitudes morales acordes al sistema republicano. El maestro, era un ardoroso defensor del desarrollo de la escuela popular o pública, obligatoria, oficial y universal para todos sin exclusiones económicas, raciales, sociales, religiosas, etc. También reconoce la importancia de la educación laica. Todas estas propuestas fueron aplicadas en su carrera como impulsor de la educación en Sudamérica, específicamente en Perú y Bolivia. El maestro Simón Rodríguez diferencia claramente las significaciones de educación e instrucción. La educación va dirigida a la formación de cualidades de 
la personalidad como son la moral y la conducta; se caracteriza, además por el nivel de desarrollo del intelecto y de las capacidades creadoras del hombre. La instrucción presupone determinado nivel de preparación del individuo para su participación en una u otra esfera de la actividad laboral.

\section{Simón Bolívar su Pensamiento y la Educación (1823-1826)}

El Libertador tuvo en su formación integral de nińo, una serie de maestros importantes; su familia los podía contratar por pertenecer a un grupo social oligárquico, Salcedo (1973) refiere: "Entre sus preceptores tuvo a los presbíteros José Antonio Negrete y Francisco Andujar, a Guillermo Pelgrón, Fernando Vides, el licenciado Sanz, Simón Rodríguez, y a su propio compañero de infancia Andrés Bello" (p. 27). Por otra parte, respecto a la influencia en el pensamiento educativo afirma: "Los verdaderos inspiradores del Libertador en educación son al fin indudablemente identificados: Diderot, Condorcet, Helvecio, Vives, La Chalotarais" (p.106) pero sabemos que quien influencio más fue don Simón Rodríguez. Hacia 1799, llegaron a Caracas dos científicos europeos el alemán Alexander Von Humboldt y el botánico francés Aimé Bonpland, realizaban estudios científicos en las colonias americanas. En Caracas eran seguidos por la juventud porque personificaban los cambios de Europa, los acompańaba Andrés Bello quien presentó a su pupilo Simón Bolívar. Posteriormente se encontrarían en Europa cuando Bolívar paseaba por estos lares; lo que demuestra que el Libertador era un hombre que gustaba conocer los avances científicos y tecnológicos de su época.

Un importante documento de Bolívar es su discurso pronunciado el 15 de febrero de 1819 en el Congreso de Angostura, convocado por él mismo en su condición de Jefe Supremo de la República de Venezuela. Sus líneas hacen una explícita mención de las ideas políticas democráticas, republicanas y educativas. El interés por la moral, lo llevó a proponer la creación de un Poder Moral, concebido como un tribunal o cuarto poder del Estado que vigilaría las violaciones del gobierno y el abandono de los deberes morales de los ciudadanos. Sería el responsable de formar al pueblo en el espíritu cívico y las virtudes políticas republicanas. Este Poder Moral residiría en el Areópago o tribunal compuesto de dos cámaras. La Cámara Moral, que dirigiría la opinión moral de toda la República, castigaría los vicios y premiaría las virtudes públicas. La Cámara de Educación estaría encargada de la educación física y moral de los niños, desde su nacimiento hasta los 12 años. A pesar del sustento dado por Bolívar, la propuesta del Poder Moral no fue aceptado por los legisladores del Congreso de Angostura. Como ha argumentado Lynch (2019), esta idea, que no encontró eco en sus contemporáneos, era un símbolo típico de la búsqueda de Bolívar de una educación política para su pueblo, algo que consideraba tan importante como para requerir una institución dedicada a 
promoverla (p. 164). La actitud del Libertador es paradigmática, siempre estuvo presente el interés por el desarrollo de una educación pública, general y gratuita, con el objetivo de consolidar la república; igualmente refiriéndose a Bolívar dice “...ese era el hombre que, con nada y solemne sencillez, consideraba a la educación y a la instrucción pública "el principio más seguro de la felicidad general y las más sólida base de la libertad de los pueblos" (p.204); el Libertador considera que la educación y la instrucción es el único camino para construir una sociedad libre y republicana. Cabe señalar que para Bolívar los colegios debían estar divididos en masculinos y femeninos, al menos hasta que la razón empezase a obrar en ambos grupos de adolescentes, este sistema se había aplicado en la Francia revolucionaria, la coeducación recién seria planteado a fines del s. XIX e inicios del XX en los EE. UU.

En la Gran Colombia el Libertador demostró su preocupación para reivindicar a los hijos de los sectores desposeídos y marginados de la sociedad colombiana, además asume que el funcionamiento de las escuelas debe ser responsabilidad del Estado. Con el decreto ley del 2 de agosto de 1821, sancionado por el Congreso de Cúcuta, estableció los principios educativos resumida por Soasti (2007) de la manera siguiente:

Educación de todos los ciudadanos para el progreso del "Estado" y la felicidad pública. Responsabilidad esencial del "Estado" en la educación de los habitantes y de los padres en la educación de sus hijos. Obligatoriedad de los padres de enviar a sus hijos a la escuela primaria. Derecho de los padres de dar a sus hijos la educación que a bien tuvieran. Un método de enseñanza uniforme en toda la República. Preocupación especial por la educación femenina e indígena. (p.152)

Bolívar, para cumplir con todos estos principios estableció escuelas, de primeras letras, en todas las ciudades, villas, parroquias y pueblos incluido las comunidades indígenas, que tuvieran por lo menos cien vecinos. La financiación estuvo a cargo de las municipalidades, con el aporte de los vecinos. Para el logro y éxito de la educación pública, creó las condiciones necesarias, a través de una serie de disposiciones como el de liberar impuestos a la importación de libros, mapas, utensilios de laboratorios, máquinas, herramientas, instrumentos para la manufactura y navegación, etc.

En cuanto a la necesidad de vincular el trabajo productivo a los estudios teóricos, Bolívar (1974a) expresó en la carta su interés por la enseñanza técnica, pues "abundan entre nosotros médicos y abogados, pero nos faltan buenos mecánicos y agricultores que son los que el país necesita para adelantar en prosperidad y bienestar" (p. 67). Estas profesiones eran necesarias en el devenir de las nuevas repúblicas; sin embargo, lo señala claramente Mariátegui (1968) la herencia colonial continuo con la formación de abogados, doctores, oficinistas, literatos y maestros que no contribuyen al desarrollo del país (p.88). 
Bolívar, en Quito hizo una serie de cambios en bien de la educación y reivindica la cultura indígena; Salcedo (1973) refiere: “...incluye en el programa de reforma de la Universidad de Quito el estudio de la lengua quechua, junto al de las lenguas francesa, inglesa, latina y castellana" (p.98). Reivindica el idioma quechua y lo pone al mismo nivel que los idiomas extranjeros, igualmente dio disposiciones para la conservación de monumentos históricos de los incas.

\section{La Labor Educativa de Simón Bolívar en el Perú}

Durante su gobierno se caracterizó por un importante despliegue de políticas educativas, las cuales tuvieron dos grandes influencias en su ejecución: por un lado, el método lancasteriano, materializado en las escuelas normales, instituciones que formarían a los maestros que tomarían las riendas de las escuelas públicas del Perú y por otro lado, el proyecto de educación popular de Simón Rodríguez, que buscó una democratización de la enseñanza en todas las castas de la sociedad.

\section{Primeras Medidas Educativas de Simón Bolívar (1823-1824)}

Lo realizo antes de la batalla de Ayacucho, acontecimiento hito en el proceso de independencia peruana, la contienda armada predominó de forma omnímoda, adicionando a ello los conflictos políticos internos y la desconfianza. A pesar de ello, Bolívar no dejó de lado el fundamental problema de la educación. En plena marcha por la sierra norte del país, en el Cuartel General de Huamachuco dictó el decreto de creación de la Universidad de Trujillo,0020el 10 de mayo de 1824. Fue una de las primeras medidas educativas del gobierno de Bolívar, también firmada por Faustino Sánchez Carrión. El decreto consideró que la universidad era uno de los medios más eficaces para promover la instrucción pública, "de la que dependen en mucha parte el sostenimiento y seguridad de los derechos sociales" (Bolívar, 1824, 31 de julio, p. 1). La fundación se hizo en acatamiento de lo ordenado por la Constitución de 1823, que normaba que todas las poblaciones de la República tienen derecho a los establecimientos de instrucción y universidades en las capitales de departamentos.

Además, el decreto señalaba que Trujillo merecía mucho de la patria "por su fidelidad a la causa, y por sus multiplicados importantes servicios al ejército libertador en las circunstancias más apuradas de la República” (Bolívar, 1824, 31 de julio, p. 1). Cabe mencionar que la Universidad de Trujillo era la cuarta Universidad del país y la primera y única fundada por el Libertador, en el Perú. Salcedo (1968) con suma claridad refiere: "El primer documento bolivariano referido a la educación superior es el decreto - del 
10 mayo de 1824 - declarando erigida la Universidad de Trujillo, en el Perú" (p.189). Fueron nombrados rector y tesorero del establecimiento los doctores Carlos Pedemonte y Pablo Madalengoitia, respectivamente. El rector debía colaborar en la redacción de sus estatutos con Hipólito Unanue, Manuel Lorenzo de Vidaurre y Manuel de Villarán, documento que en última instancia debía ser elevado al gobierno para su aprobación oficial.

Basadre (1982.T.I) refiere "Con fecha 14 de abril de 1825, el Libertador dejo constancia del "completo abandono en que se halla la educación pública en todos los pueblos del Perú. En ninguno hay escuelas ni de primeras letras y los niños y jóvenes crecen en la más absoluta ignorancia" (p.161). Sin embargo, las atenciones de la campańa de independencia peruana y las sucesivas metamorfosis a que estuvo sujeto el Perú en los años siguientes, retardaron el desarrollo de políticas educativas y la instalación de la Universidad de Trujillo. Bajo el nombre de Universidad de Santo Tomás y Santa Rosa, recién empezó su funcionamiento el 12 de octubre de 1831, normándose por las constituciones de la Universidad de San Marcos.

Después de la victoria de Junín, habiendo establecido su Cuartel General en Huancayo, el 20 de agosto de 1824, ordenó, que se cumpliera con el Decreto del 23 de febrero de 1822, que establecía en todos los conventos regulares del Perú, funcionaran escuelas gratuitas de primeras letras. El preceptor o profesor debía ser un fraile designado por el superior de cada convento. Dispuso que los preceptores reciban un sueldo de acuerdo con el espíritu de trabajo, virtudes y honorabilidad que exhibiera, los cuales debían ser comprobados por los prelados de cada convento y por los municipios de cada lugar. Cuando Bolívar, se desplazó de Huancayo a Huamanga, en Tarma el dominico patriota fraile Vicente Ortiz, que había edificado la capilla del Señor de la Cárcel, fundó (1824) y dirigió la primera escuela básica.

Otro importante decreto fue el dado en Canta, Lima, del 1 de noviembre de 1824, firmado por Bolívar y Sánchez Carrión, mandaba transformar el colegio de misioneros de Santa Rosa de Ocopa, Junín, en un establecimiento de enseñanza pública. Este plantel estaba dedicado exclusivamente a misioneros españoles, por entonces se encontraba olvidado. Según el decreto, su transformación en un colegio de enseñanza pública también respondía a que "la educación pública está totalmente abandonada en el Valle de Jauja; y que esta debe cultivarse, con esmero, entre una juventud, cuyos padres han sido sacrificados por la causa de la libertad" (Bolívar, 1825, 3 de marzo). Resulta interesante que tanto en la creación de la Universidad de Trujillo como en la del Colegio de Santa Rosa de Ocopa ${ }^{1}$ se empleó el discurso patriótico.

1 El 11 de marzo de 1936, el Convento de Ocopa, por gestión del arzobispo de Lima, Don Jorge Benavente, fue restablecido, en sus antiguas funciones por orden gubernamental. 
Vencidas las armas espańolas en Ayacucho, el 9 de diciembre de 1824, el Libertador pensó en mejorar la situación educativa del Perú. En 1825, la legislación bolivariana en materia educativa creció considerablemente. Una de las primeras medidas fue la implementación de escuelas normales en el país. Por decreto en Lima del 31 de enero de 1825, firmado juntamente con su ministro Sánchez Carrión, Bolívar mandó establecer en la capital de cada departamento una Escuela Normal, de método lancasteriano o de enseńanza mutua. La administración de los fondos para el funcionamiento de estos establecimientos correría de parte de los prefectos y municipalidades. Además, disponía que cada provincia debía de mandar a la escuela de su departamento al menos 6 niños, para que estos difundan, después, la enseñanza en los pueblos del interior, estos eran denominados monitores.

Al Perú el método lancasteriano fue traído por el educador escocés James o Diego Thompson, cuyos servicios fueron solicitados por José de San Martín en 1822 para establecer las primeras escuelas lancasterianas y la primera Escuela Normal del país, creada por decreto del 6 de julio de 1822, firmado por el Supremo Delegado Bernardo de Monteagudo.

A pesar de los intentos mencionados, a inicios de 1825 la instrucción en el Perú se encontraba en un estado de olvido, debido a los gastos deducidos de la guerra de independencia, que no permitía la formación de escuelas, era necesario que los prefectos de cada departamento inciten a los padres de familia a contribuir con parte de su pecunio para la erección de las escuelas normales. Si bien la preocupación del Libertador por la educación popular en el Perú fue explícita en su accionar, su abandono del país en 1826 y la crisis política que continuó al menos hasta 1845 impidieron un correcto desarrollo de lo educativo en el territorio nacional.

El maestro Rodríguez, después de su exilio, regresó a Sudamérica en 1823, a Colombia; en Bogotá estableció una escuela en el edificio del antiguo hospicio, con apoyo del vicepresidente Santander. Enterado el Libertador de tan grata noticia, solicitó al vicepresidente, que le dé facilidades económicas, para que viaje al Perú; lo señala en la carta escrita en el vellorio de Pallasca, el 9 de diciembre de 1823:

He sabido que ha llegado de París un amigo mío, don Simón Rodríguez; si es verdad haga usted por él cuanto merece un sabio y un amigo mío que adoro. Es un filósofo consumado y un patriota sin igual; es el Sócrates de Caracas [...] Dígale usted que me escriba, y dele dinero de mi parte librándolo contra mi apoderado en Caracas. Si puede, que me venga a ver. (Bolívar, 1823, como se citó en Rumazo, 2005, pp. 101-102)

Poco después, el 19 de enero de 1824, desde Pativilca, donde se encontraba recuperándose de sus males, el Libertador le escribió a su maestro una emotiva epístola, importante documento para estudiar la obra educativa de Rodríguez y su relación con Bolívar. 
Sus líneas reflejan el gran respeto que tenía el general por su antiguo maestro, llena de elogios y referencias a la amistad de ambos personajes, resaltando el gran impacto que el maestro le generó

Tan solo el comienzo del escrito nos da una idea de ello, en donde Bolívar (1824, como se citó en Rumazo, 2005) señala: “¡Oh, mi maestro! ¡Oh mi amigo! ¡Oh mi Robinson [haciendo alusión a su apodo durante su permanencia en Europa] [...] Sin duda es usted el hombre más extraordinario del mundo" (p. 103). La carta recuerda acontecimientos como el juramento del futuro Libertador en el Monte Sacro (Roma, 1805) y el impacto de la enseńanza de Rodríguez en Bolívar. Finalmente, el maestro y alumno protagonizan un emotivo encuentro en Magdalena, Lima a inicios de 1825, dándose un jubiloso abrazo.

La llegada de Rodríguez fue oportuna, Bolívar se alistaba para viajar al sur del Perú y deseaba establecer escuelas que las que pondría bajo la dirección de su amigo. Para ello, el Libertador lo nombró director e Inspector General de Instrucción Pública y de Beneficencia equivalente a Ministro de Educación, le encarga dirigir la instrucción escolar en el Perú. El 11 de abril de 1825, cuando el Libertador se encontraba en el cenit de su gloria en compañía de su maestro y amigo y su comitiva partieron de Lima rumbo a las ciudades, pueblos del sur del Perú y a la Paz, capital del Alto Perú, en cuyo camino, recibieron sendos homenajes y en las principales ciudades, establecieron casas de educación popular para nińas y niños. En Arequipa, que tenía fama de ser conservadora y fidelista. Llego el 10 de mayo, y fue agasajado por la población y autoridades. Vargas U. (1987.T VII) refiere, que recibió, en un colegio, un valioso regalo de parte de dos hermosas niñas, a quienes le dijo: "Hijas del Sol. Ya sois tan libres como hermosas. Tenéis una patria iluminada por las armas del ejército libertador; libres son vuestros padres y vuestros hermanos, libres serán vuestros esposos y libres daréis al mundo los frutos de vuestro amor" (p.66). Reconocimiento del Libertador a la libertad y él obispo Goyeneche, le rindió pleitesía y se ganó la confianza de Bolívar.

El Libertador, también realizó obra educativa a través del Consejo de Gobierno en 1825. Para controlar y orientar la educación peruana y las próximas medidas a tomarse en el camino hacia el sur del Perú, decretó el 25 de abril de 1825, a través de su Consejo de Gobierno en Lima, la creación de la Dirección General de Estudios, presidida por el rector de la Universidad de San Marcos, teniendo como vocales a los rectores de los colegios limeños de San Carlos, Santo Toribio e Independencia, un protomédico y el decano del Colegio de Abogados.

El interés del Consejo de Gobierno de Bolívar por la educación en el Perú lo llevó a convocar interesantes concursos de becas, como el de mayo de 1825 . El objetivo era enviar a diez jóvenes a Inglaterra para que aprendan lenguas europeas, derecho público y economía política, además de los conocimientos básicos que un diplomático o político competente necesitaría. Entre los ganadores figurarían cuatro de Lima y dos de La 
Libertad, Cuzco y Arequipa, respectivamente. El 20 de octubre, fueron enviados, para que se eduquen en los mejores colegios a cuenta del Estado.

Con respecto a la educación indígena, no se había dado ninguna medida desde la proclamación de la independencia hasta el ascenso de Bolívar al poder. Por decreto del 15 de mayo de 1825, el Consejo de Gobierno de Bolívar en Lima restauró el antiguo colegio de indígenas nobles El Príncipe, renombrándolo como La Libertad. El fundamento del decreto defendía que "la instrucción debe ser general en todas las clases que habitan el Perú, y especialmente entre sus antiguos indígenas, que han hecho tan gloriosos esfuerzos por la libertad" (Consejo de Gobierno, 1825, 19 de mayo p. 4). Su rector, José Ignacio Moreno, debía elaborar un plan de estudios más extensivo y moderno que el heredado de los españoles. Observamos el interés descolonizador y peruanizador de parte del Consejo de Gobierno y Bolívar. La Libertad, tuvo una efímera vida, por decreto del 20 de setiembre de 1825, se fusionó con el Colegio de San Carlos, bajo el nombre de Convictorio de Bolívar, en honor al Libertador. La medida, firmada por Unanue (1825a, 22 de setiembre), tenía como objetivo que "los hijos de los antiguos indígenas del Perú tengan una misma educación y rango que los de los españoles que después le poblaron" (p. 2).

Como se observa hasta aquí, tanto el colegio de La Libertad como el Convictorio de Bolívar tuvieron entre sus objetivos el de extender la educación indígena a todas las realidades, tanto de jóvenes provenientes de familias nobles como de los estratos menos acomodados, colocándolos en el mismo nivel que otros grupos sociales. Con la creación del colegio de La Libertad y el Convictorio de Bolívar, se nota un cambio importante en la relación entre el Estado y la población indígena en la naciente república, aunque no tuviesen el éxito deseado a largo plazo.

El Libertador en su viaje al Cuzco fue recibido de manera apoteósica, al contemplar las ruinas de las grandiosas construcciones incaicas según Lavretski (1982) observó: "Estas ruinas de bellísimos palacios y templos hacen que recordemos nuestras obligaciones para con los descendientes de quienes las construyeron" (p.139). En compañía de su maestro Rodríguez, el 8 de julio de 1825, fundaron el Colegio de Educandas, reivindicaban un nuevo capítulo en la educación femenina del país. El decreto fue firmado por Bolívar y su ministro Felipe Santiago Estenós. En el establecimiento se admitirían niñas de cualquier clase, tanto de la ciudad del Cuzco como del interior del departamento, que estén en aptitud de recibir la educación. Además, el decreto consideraba que la educación de las niñas era la "base de la moral familiar», por lo que "es forzoso dictar providencias para poner cuanto antes en planta un establecimiento tan necesario" (Bolívar, 1825a, 4 de setiembre, p. 1).

El Colegio de Educandas fue puesto a funcionar por el prefecto del Cuzco Agustín Gamarra en 1827; sin embargo, desde su apertura, pasó por ciclos de depresiones y auges inseguros, de acuerdo con el devenir del proceso histórico local y nacional. Fue 
el primer colegio para mujeres, creado en el periodo republicano sin distingo de raza o clase; guardó cercanía con las propuestas de Rodríguez: la educación popular y la educación femenina para la formación moral.

El Consejo de Gobierno en Lima, presidido por Unanue, por orden de Bolívar, expidió un decreto el 5 de octubre de 1825 creando un gineceo en la capital, es decir, una escuela para mujeres jóvenes en el Convento de la Concepción, al año siguiente adopto el nombre de Escuela Lancasteriana para Mujeres. En la educación femenina estaba muy presente la religión, se consideraba que la mujer tenía una importante función en la edificación de la moral y espíritu religioso de los pueblos. Para el naciente Estado republicano peruano, la mujer cumplía una función adicional, además de educar al futuro peruano: buscar desterrar "los vicios del coloniaje" y la "fatal esclavitud que trajo consigo" (Unanue, 1825, 9 de octubre, p. 1).

El Libertador en el Cuzco, por decreto del mismo día, 8 de julio de 1825, mandó a erigir un colegio público dedicado a la enseñanza de ciencias y artes, conocido con el nombre de Colegio del Cuzco o Colegio de Ciencias y Artes del Cuzco. Este vendría a llenar un vacío en la región, pues, como menciona el decreto, "la Educación de la juventud se halla casi abandonada por la insuficiencia de los establecimientos destinados a tan interesante objeto" (Bolívar, 1825b, 4 de setiembre, p. 1).

El Colegio del Cuzco fue resultado de la fusión de dos antiguos colegios coloniales: el Colegio San Francisco de Borja, dedicado a la educación de los hijos de la nobleza incaica y de los caciques o curacas; y el Colegio Real de San Bernardo, institución jesuita creada para la educación de los hijos de españoles. Fue en el local de este último en el que funcionó el Colegio del Cuzco, junto con el Colegio de Educandas. Resulta visible la influencia de Rodríguez en Bolívar en la creación de esta institución educativa, pues buscó que, en dicho establecimiento, educara a los peruanos patriotas sin distinguirlos socialmente, sean descendientes de incas o de españoles: es decir, para todas las sangres.

En dos decretos dados el 19 de julio de 1825 en Urubamba, el Libertador mandó a crear en el Cuzco dos hospicios o albergues, uno para expósitos y huérfanos, y otro para mendigos y discapacitados de ambos sexos; así, el primero fue establecido en la casa de San Buenaventura, mientras que el segundo en una casa que sería el hospital (Bolívar, 1825a, 8 de setiembre, p. 1; 1825b, 8 de setiembre, p. 1). Estas normas son una muestra de la preocupación de Rodríguez por la educación de los niños expósitos, huérfanos y mendigos. Con esto, como reconoce Maziláo (2018), se buscaba responder a un problema social de larga data en la región cuzqueña, a saber, la gran cantidad de nińos de la calle que se quedaron sin hogar: muchos de ellos quedaron huérfanos de padres que fueron víctimas de la guerra de la independencia peruana y serían tratados, en ausencia de la escuela, como un problema policial (pp. 78-79). Estos hospicios o albergues, además de sacar a los mendigos y niños de las calles, les darían educación 
de la que hasta entonces habían estado privados, haciéndolos ciudadanos útiles para la naciente república.

Bolívar en su camino al Alto Perú, en el pueblo de Pucará (Puno), el 2 de agosto de 1825, recibió un homenaje de José Domingo Choquehuanca, quien pronunció una arenga en favor del Libertador. Por decreto del 7 de agosto de 1825 Bolívar (1825, 27 de agosto) mandó crear el primer establecimiento de educación pública en dicha región: el Colegio de Ciencias y Artes de Puno. Las rentas para el funcionamiento del colegio vendrían de los diezmos de las provincias de Chucuito y Huancané, el producto de determinadas haciendas del departamento y de la mina de Salcedo. El decreto también estableció una escuela de nińas en Puno y escuelas de primeras letras en todas las parroquias de la región costeadas por el vecindario

El Libertador, por decreto del 20 de setiembre de 1825, a través del Consejo de Gobierno estableció en la capital un Colegio Central de Humanidades. Reponían para la juventud de la nueva república dichos estudios, paralizados por la guerra de independencia. Se restablecieron tres aulas de humanidades en la primera se enseñe la lengua castellana; en la segunda la gramática latina hasta concluir la sintaxis; y en la última se perfeccionen los jóvenes en la traducción, y reciban lecciones de poesía y retórica. Como director de las tres aulas quedó nominado José Ignacio Moreno.

El Libertador siempre guardó un profundo respeto a la labor docente, sin embargo, adolecía de una serie de problemas como la impuntualidad en los pagos y otros. Para remediar dicha situación, por decreto del 20 de setiembre de 1825, a través del Consejo de Gobierno, mandó a que la Dirección General de Censos y Obras Pías se encargara de recolectar todas las entradas destinadas al ramo de educación, las cuales venían del gravamen de distintas haciendas y propiedades (Unanue, 1825c, 22 de setiembre, p. 3). Es decir, centralizó la administración de los ingresos destinados a lo educativo. Además, indicó que el director de Temporalidades debía de abonar con puntualidad el sueldo de los docentes.

El cultivo de las artes formó parte de los intereses del periodo bolivariano. Ello se reflejó en el decreto dado por el Consejo del Gobierno de Lima el 2 de diciembre de 1825, el cual concedió a la Sociedad Filarmónica la capilla de la extinguida Inquisición, para la enseńanza y ejercicio del arte musical (Unanue, 1825, 4 de diciembre, p. 1). El edificio principal debería ser empleado para el desarrollo de conciertos de música. Por su parte, los dos salones siguientes de la Inquisición se dedicarían a sostener un Museo de la Pintura, en donde se expondrán los cuadros de propiedad del Estado.

Otro museo organizado por el Consejo de Gobierno fue el de Historia Natural, museo que había quedado proyectado en 1822, pero por la guerra de independencia quedó sin concretarse. En una circular de Lima del 8 de abril de 1826, firmada por José Serra, se informó del interés por parte del Consejo, de establecer el museo, para proporcionar a la juventud, material de estudio sobre la naturaleza de seres orgánicos é 
inorgánicos. La circular también especificó los objetos que debían remitirse al Museo desde las distintas partes del Perú: minerales cristalizados, mármoles y rocas; conchas de las riveras del mar; cuadrúpedos, vivos o disecados; plantas medicinales; finalmente, tejidos y objetos extraídos de las huacas. Todo ello bajo ciertos cuidados de conservación, también indicados en el documento. Además, indicó como nuevo director del establecimiento a Mariano Rivero.

\section{Referencias}

Amunategui, D. (1895). Sistema de Lancaster en Chile I En Otros Países Sud Americanos. Santiago. Imprenta Cervantes.

Basadre. J. (1963). Historia de la República del Perú (1822-1933) Lima- Editorial Universitaria. Colección Documental de la Independencia del Perú (T.V). La acción patriótica del Pueblo en la Emancipación. Guerrillas y Montoneras. Lima. Comisión Nacional del Sesquicentenario de la Independencia del Perú.

Caro, G. (2006). La Escuela de Estudio y Trabajo en Coeducación. Lima. Fondo Editorial del Pedagógico de San Marcos.

Cervantes, F. (2018). Sociedades Americanas en 1828. Cómo serán y cómo podrían ser en los siglos venideros de Simón Rodríguez. México: Universidad Autónoma Metropolitana.

García, B. (2010). Pensamiento de Simón Rodríguez: La educación como proyecto de inclusión social. Revista Colombiana de Educación, (59), 134-147. https://revistas.pedagogica.edu.co/ index.php/RCE/article/view/600

Glave, L. M. (2013). Colección Pensamiento Educativo Peruano. Volumen 2: Entre la sumisión y la libertad, siglo XVII-XVIII. Lima: Derrama Magisterial.

Grigulévich, I. (1988). Luchadores por la libertad de América Latina. Moscú. Editorial Progreso. Lavretski, I. (1966). Simón Bolivar. Moscú. Editorial Progreso.

Lynch, J. (2019). Simón Bolivar. Barcelona: Crítica.

Mariátegui, J.C. (1968). 7 ensayos de Interpretación de la Realidad Peruana. Lima. Biblioteca Amauta

Mazilāo, A. (2018). A política educacional de Simón Rodríguez para a República do Peru (1825). Desde el Sur, 10(1), 67-92. https://revistas.cientifica.edu.pe/index.php/desdeelsur/ article/view/430

Mendoza, C. L. (Ed.) (1964). Escritos del Libertador. Tomo I: Introducción general. Caracas: Sociedad Bolivariana de Venezuela.

Ocampo L.J. (2007). Simón Rodríguez el Maestro del Libertador. Bogotá. Revista Historia de la Educación Latinoamericana Universidad Pedagógica y Tecnológica de Colombia.

Peńaloza, W. (2001) Por una Reforma Educativa adecuada a nuestra realidad nacional. En Las Reformas Educativas en Perú, América Latina y el Caribe. Lima. Pedagógico de San Marcos. 
Quiroz, M. (2020). Independencia y educación: La Universidad de Santo Tomás y Santa Rosa en la ciudad de Trujillo (1824-1876). En F. San Martín y V. Dieguez (eds.), Trujillo: Capital de la Independencia del Perú (pp. 339-362). Trujillo: Imprenta Editora Grafica Real.

Rumazo Gonzáles, A. (2005). Simón Rodríguez: Maestro de América. Caracas: Biblioteca Ayacucho.

Salcedo B. J.L. (1973). El Primer Deber Con el Acervo Documental de bolivar sobre Educación y la Cultura. Caracas. Ediciones Equinoccio.

Sánchez G, (2009). El pensamiento pedagógico y politico de don Simón Rodríguez visto a la luz de la educación popular. Quito. Tesis de maestría. Universidad Andina Simón Bolívar.

Soasti, G. (2007). La Republica Peregrina. Hombres de armas y letras en América del Sur 1800 1884. Lima. Instituto Frances de Estudios Peruanos. IEP.

Vargas, R. (1987 T.VII). Historia General del Perú. La República. Lima. Editorial Milla Batres.

Valcárcel, C. D. (1974). Obra educativa de Bolivar y su recibimiento en San Marcos. Lima: Universidad Nacional Mayor de San Marcos. 